\title{
Editorial: Inner Experiences: Theory, Measurement, Frequency, Content, and Functions
}

\author{
Alain Morin $^{1 *}$, Jason D. Runyan ${ }^{2}$ and Thomas M. Brinthaupt ${ }^{3}$ \\ ${ }^{1}$ Department of Psychology, Mount Royal University, Calgary, AB, Canada, ${ }^{2}$ Department of Psychology, Indiana Wesleyan \\ University, Marion, IN, USA, ${ }^{3}$ Department of Psychology, Middle Tennessee State University, Murfreesboro, TN, USA
}

Keywords: resting state, mind wandering, inner speech, unsymbolized thinking, fMRI methods, thought sampling, self-report instruments

It is safe to posit that human beings have been interested in their own inner mental experiences from the moment they became aware of them, arguably over 60,000 years ago (Leary, 2004). In sharp contrast, growth in the actual scientific examination of these inner experiences is remarkably recent (e.g., Csikszentmihalyi and Figurski, 1982; Klinger and Cox, 1987-1988; Goldstein and Kenen, 1988; Hurlburt, 1990). Inner speech, in particular, has been the focus of even more recent efforts (e.g., Morin et al., 2011; Brinthaupt and Dove, 2012; Hurlburt et al., 2013; Alderson-Day and Fernyhough, 2015; Alderson-Day et al., 2015). We present 14 articles that cover theoretical ideas as well as current research results pertaining to the measurement, frequency, content, and functions of inner experiences. In what follows we summarize some exciting key findings highlighted in this research topic.

\section{OPEN ACCESS}

Edited and reviewed by: Eddy J. Davelaar,

Birkbeck, University of London, UK

*Correspondence:

Alain Morin

amorin@mtroyal.ca

Specialty section:

This article was submitted to

Cognitive Science,

a section of the journal

Frontiers in Psychology

Received: 09 October 2015 Accepted: 02 November 2015 Published: 23 November 2015

Citation:

Morin A, Runyan JD and Brinthaupt TM (2015) Editorial: Inner Experiences: Theory, Measurement, Frequency, Content, and Functions. Front. Psychol. 6:1758 doi: 10.3389/fpsyg.2015.01758

\section{CONTENT AND FUNCTIONS OF INNER EXPERIENCES/INNER SPEECH}

There are large individual differences in inner experiences (i.e., inner speech, inner seeing, unsymbolized thinking, feelings, sensory awareness). In particular, resting states (relaxing without falling asleep with eyes open) seem to differ substantially from one participant to the next (Hurlburt et al., 2015). The resting state includes several distinct dimensions such as thinking about others' mental states, planning, sleepiness, bodily awareness, inner speech, mental imagery, and health concerns (Diaz et al., 2014). Inner speech probably represents a speaking activity that does not have a proper function in cognition. Rather, it inherits the array of functions of outer speech (Martínez-Manrique and Vicente, 2015). Furthermore, the relation between inner and outer speech is more complex than initially thought-e.g., patients with inner speech deficits can still overtly name objects (Langland-Hassan et al., 2015).

\section{MEASUREMENT OF INNER EXPERIENCES}

Many existing self-consciousness scales measure various related-yet different-self-reflective constructs such as adaptive-maladaptive, public-private self-consciousness, and mindfulness (DaSilveira et al., 2015). Smartphone technology allows us to significantly refine current thought sampling methods (e.g., ecological momentary assessment)-e.g., by gathering repeated sampling within various situations of daily life in very large samples, and allowing the capture of dispositional expressions (Runyan and Steinke, 2015). Repeated sampling can also promote self-awareness and 
mindfulness. Also, inner speech measured with self-report questionnaires and thought sampling procedures poorly correlate, suggesting that self-report approaches may not be valid (Alderson-Day and Fernyhough, 2015; also see Uttl et al., 2011). One exception is the Self-Talk Scale, which exhibits good psychometric qualities in multiple studies (Brinthaupt et al., 2015).

\section{MEMORY, TIME PERCEPTION, AESTHETIC EXPERIENCE, AND IMAGINATION}

When compared to younger participants, older adults report more details (e.g., when and where of events, emotions experienced, people and objects involved) in their remote/recent autobiographical memories (Gardner et al., 2015). Delayed video presentations of one's own body image alters time perception (Fritz et al., 2015). Aesthetic insight (i.e., the "aha" phenomenon) occurs as artistic material becomes more complex and determinate, increases liking, and is preceded

\section{REFERENCES}

Abraham, A., and Bubic, A. (2015). Semantic memory as the root of imagination. Front. Psychol. 6:325. doi: 10.3389/fpsyg.2015.00325

Alderson-Day, B., and Fernyhough, C. (2015). Inner speech: development, cognitive functions, phenomenology, and neurobiology. Psychol. Bullet. 141, 931-965. doi: 10.1037/bul0000021

Alderson-Day, B., Weis, S., McCarthy-Jones, S., Moseley, P., Smailes, D., and Fernyhough, C. (2015). The brain's conversation with itself: neural substrates of dialogic inner speech. Soc. Cogn. Affect. Neurosci. doi: 10.1093/scan/nsv094. [Epub ahead of print].

Brinthaupt, T. M., Benson, S. A., Kang, M., and Moore, Z. D. (2015). Assessing the accuracy of self-reported self-talk. Front. Psychol. 6:570. doi: 10.3389/fpsyg.2015.00570

Brinthaupt, T. M., and Dove, C. T. (2012). Differences in self-talk frequency as a function of age, only-child, and imaginary childhood companion status. J. Res. Person. 46, 326-333. doi: 10.1016/j.bbr.2011. 03.031

Csikszentmihalyi, M., and Figurski, T. (1982). Self-awareness and aversive experience in everyday life. J. Person. 50, 14-26. doi: 10.1111/j.14676494.1982.tb00742.x

DaSilveira, A., DeSouza, M. L., and Gomes, W. B. (2015). Self-consciousness concept and assessment in self-report measures. Front. Psychol. 6:930. doi: 10.3389/fpsyg.2015.00930

Diaz, B. A., Van Der Sluis, S., Benjamins, J. S., Stoffers, D., Hardstone, R., Mansvelder, H. D., et al. (2014). The ARSQ 2.0 reveals age and personality effects on mind-wandering experiences. Front. Psychol. 5:271. doi: 10.3389/fpsyg.2014.00271

Fritz, T. H., Steixner, A., Boettger, J., and Villringer, A. (2015). Losing track of time through delayed body representations. Front. Psychol. 6:405. doi: 10.3389/fpsyg.2015.00405

Gardner, R. S., Mainetti, M., and Ascoli, G. A. (2015). Older adults report moderately more detailed autobiographical memories. Front. Psychol. 6:631. doi: 10.3389/fpsyg.2015.00631

Goldstein, G., and Kenen, R. (1988). "Internal dialogue" in a "normal" population: the implications for health promotion. Health Promot. Int. 3, 249-257.

Hurlburt, R. T. (1990). Sampling Normal and Schizophrenic Inner Experience. New York, NY: Plenum Press. by increased interest, supporting the theory that interest is increased by the expectation of understanding (Muth et al., 2015). Imagination and creative thought likely emerge from the conceptual and factual knowledge accumulated throughout our lives-our semantic learning (Abraham and Bubic, 2015).

Based on the 14 articles presented here, we suggest that future work on inner experiences expand on (a) futureoriented thinking, (b) naturally occurring mentalizing, (c) mindfulness, (d) abnormal manifestations of inner experiences, (e) correlations between inner experiences and actual behavior, (f) inner experience changes with age, (g) inner experiences in altered states of mind and religious states, as well as (h) in infants and non-human animals.

\section{AUTHOR CONTRIBUTIONS}

AM wrote the editorial; JR and TB edited it.

Hurlburt, R. T., Alderson-Day, B., Fernyhough, C., and Kühn, S. (2015). What goes on in the resting-state? A qualitative glimpse into resting-state experience in the scanner. Front. Psychol. 6:1535. doi: 10.3389/fpsyg.2015.01535

Hurlburt, R. T., Heavey, C. L., and Kelsey, J. M. (2013). Toward a phenomenology of inner speaking. Conscious. Cogn. 22, 1477-1494. doi: 10.1016/j.concog.2013.10.003

Klinger, E., and Cox, W. M. (1987-1988). Dimensions of thought flow in everyday life. Imaginat. Cognit. Person. 7, 105-128.

Langland-Hassan, P., Faries, F. R., Richardson, M. J., and Dietz, A. (2015). Inner speech deficits in people with aphasia. Front. Psychol. 6:528. doi: 10.3389/fpsyg.2015.00528

Leary, M. R. (2004). The Curse of the Self: Self-Awareness, Egoism, and the Quality of Human Life. New York, NY: Oxford University Press.

Martínez-Manrique, F., and Vicente, A. (2015). The activity view of inner speech. Front. Psychol. 6:232. doi: 10.3389/fpsyg.2015.00232

Morin, A., Uttl, B., and Hamper, B. (2011). Self-reported frequency, content, and functions of inner speech. Proc. Soc. Behav. J. 30, 1714-1718. doi: 10.1016/j.sbspro.2011.10.331

Muth, C., Raab, M. H., and Carbon, C.-C. (2015). The stream of experience when watching artistic movies. Dynamic aesthetic effects revealed by the Continuous Evaluation Procedure (CEP). Front. Psychol. 6:365. doi: 10.3389/fpsyg.2015.00365

Runyan, J. D., and Steinke, E. G. (2015). Virtues, ecological momentary assessment/intervention and smartphone technology. Front. Psychol. 6:481. doi: 10.3389/fpsyg.2015.00481

Uttl, B., Morin, A., and Hamper, B. (2011). Are self-report questionnaires of inner speech valid and reliable? Proc. Soc. Behav. J. 30, 1719-1723. doi: 10.1016/j.sbspro.2011.10.332

Conflict of Interest Statement: The authors declare that the research was conducted in the absence of any commercial or financial relationships that could be construed as a potential conflict of interest.

Copyright (C) 2015 Morin, Runyan and Brinthaupt. This is an open-access article distributed under the terms of the Creative Commons Attribution License (CC BY). The use, distribution or reproduction in other forums is permitted, provided the original author(s) or licensor are credited and that the original publication in this journal is cited, in accordance with accepted academic practice. No use, distribution or reproduction is permitted which does not comply with these terms. 